\title{
Prediction of Severe Bleeding after Coronary Surgery: the WILL-BLEED Risk Score
}

\section{Short title: Severe bleeding in coronary surgery}

Fausto Biancari, ${ }^{1} \mathrm{MD}, \mathrm{PhD}$, Debora Brascia, ${ }^{1} \mathrm{MD}$, Francesco Onorati, ${ }^{2} \mathrm{MD}, \mathrm{PhD}$, Daniel Reichart, ${ }^{3}$ MD, Andrea Perrotti, ${ }^{4}$ MD, Vito G. Ruggieri, ${ }^{5} \mathrm{MD}, \mathrm{PhD}$, Giuseppe Santarpino, ${ }^{6} \mathrm{MD}$, PhD, Daniele Maselli, ${ }^{7} \mathrm{MD}$, Giovanni Mariscalco,${ }^{8} \mathrm{MD}$, PhD, Riccardo Gherli, ${ }^{9} \mathrm{MD}$, Antonino S. Rubino, ${ }^{10} \mathrm{MD}$, $\mathrm{PhD}$, Marisa De Feo, ${ }^{11} \mathrm{MD}, \mathrm{PhD}$, Giuseppe Gatti, ${ }^{12} \mathrm{MD}$, Francesco Santini, ${ }^{13} \mathrm{MD}$, Magnus Dalén, ${ }^{14} \mathrm{MD}$, Matteo Saccocci, ${ }^{15} \mathrm{MD}$, Eeva-Maija Kinnunen, ${ }^{1} \mathrm{MD}, \mathrm{PhD}$, Juhani K.E. Airaksinen, ${ }^{16}$ $\mathrm{MD}, \mathrm{PhD}$, Paola D’Errigo, MSc, Stefano Rosato, MSc, and Francesco Nicolini, ${ }^{17} \mathrm{MD}, \mathrm{PhD}$

1. Department of Surgery, Oulu University Hospital, Oulu, Finland.

2. Division of Cardiovascular Surgery, Verona University Hospital, Verona, Italy;

3. Hamburg University Heart Center, Hamburg, Germany.

4. Department of Thoracic and Cardio-Vascular Surgery, University Hospital Jean Minjoz, Besançon, France;

5. Division of Cardiothoracic and Vascular Surgery, Pontchaillou University Hospital, Rennes, France;

6. Cardiovascular Center, Paracelsus Medical University, Nuremberg, Germany;

7. Department of Cardiac Surgery, St. Anna Hospital, Catanzaro, Italy;

8. Department of Cardiovascular Sciences, Clinical Science Wing, University of Leicester, Glenfield Hospital, Leicester, UK;

9. Unit of Cardiac Surgery, Department of Cardiosciences, Hospital S. Camillo-Forlanini, Rome, Italy;

10. Centro Cuore Morgagni, Pedara, Italy;

11. Division of Cardiac Surgery, Department of Cardiothoracic Sciences, Second University of Naples, Naples, Italy;

12. Division of Cardiac Surgery, Ospedali Riuniti, Trieste, Italy;

13. Division of Cardiac Surgery, University of Genoa, Genoa, Italy;

14. Department of Molecular Medicine and Surgery, Department of Cardiothoracic Surgery and Anesthesiology, Karolinska Institutet, Karolinska University Hospital, Stockholm, Sweden;

15. Department of Cardiac Surgery, Centro Cardiologico-Fondazione Monzino IRCCS, University of Milan, Italy;

16. Heart Center, Turku University Hospital, Turku, Finland;

17. National Center for Epidemiology, Surveillance and Health Promotion, Istituto Superiore di Sanitá, Rome, Italy;

18. Division of Cardiac Surgery, University of Parma, Parma, Italy.

Text word count: 2117 words

\section{For correspondence:}

Prof. Fausto Biancari,

Department of Surgery,

Oulu University Hospital,

PL 21, 90029 Oulu

Finland

E-mail: faustobiancari@yahoo.it

Phone: +358407333973

Fax: +358 83152486 


\begin{abstract}
Background: Severe perioperative bleeding after coronary artery bypass grafting (CABG) is associated with poor outcome.
\end{abstract}

Methods: An additive score for prediction of severe bleeding was derived $(n=2494)$ and validated $(n=1250)$ in patients from the E-CABG registry. Severe bleeding was defined as E-CABG bleeding grades 2-3 (transfusion of $>4$ units of red blood cells or reoperation for bleeding).

Results: The overall incidence of severe bleeding was 6.4\%. Preoperative anemia (3 points), female gender ( 2 points), eGFR $<45 \mathrm{~mL} / \mathrm{min} / 1.73 \mathrm{~m}^{2}$ (3 points), potent antiplatelet drugs discontinued less than 5 days ( 2 points), critical preoperative state ( 5 points), acute coronary syndrome ( 2 points), use of low molecular weight heparin/fondaparinux/unfractionated heparin (1 point) were independent predictors of severe bleeding. The WILL-BLEED score was associated with increasing rates of severe bleeding in both the derivation and validation cohorts (scores $0-3: 2.9 \%$ vs 3.4\%; scores 4-6: $6.8 \%$ vs $7.5 \%$; scores $>6: 24.6 \%$ vs $24.2 \%$, both $\mathrm{p}<0.0001$ ). The WILL-BLEED score had a better discriminatory ability (AUC 0.725 ) for prediction of severe bleeding compared to the ACTION (AUC 0.671), CRUSADE (AUC 0.642), Papworth (AUC 0.605), TRUST (AUC 0.660) and TRACK (AUC 0.640) bleeding scores. The net reclassification index and integrated discrimination improvement using the WILL-BLEED score as opposed to the other bleeding scores were significant $(\mathrm{p}<0.0001)$. The decision curve analysis demonstrated a net benefit with the WILLBLEED score compared to the other bleeding scores.

Conclusions: The WILL-BLEED risk score is a simple risk stratification method which allows the identification of patients at high risk of severe bleeding after CABG.

Clinical Trial Registration: NCT02319083 (https://clinicaltrials.gov/ct2/show/NCT02319083) Abstract word count: 250 words.

Key words: Bleeding; coronary artery bypass grafting; CABG; cardiac surgery; risk score. 


\section{Introduction}

Severe perioperative bleeding is associated with poor outcome in patients undergoing cardiovascular procedures. ${ }^{1-3}$ Identification of patients at increased risk of perioperative bleeding is important to adopt measures to reduce perioperative blood loss as well as the exposure to blood products. A bleeding risk score would be of particular importance in patients undergoing coronary artery bypass grafting $(\mathrm{CABG})$ as they are frequently treated with potent antithrombotics and are in need of effective measures to reduce excessive perioperative bleeding. Furthermore, a valid risk score would be helpful to address the risk of severe bleeding in case of medicolegal litigations. A number of scoring methods are available for bleeding risk prediction during percutaneous coronary interventions $^{5-8}$ and adult cardiac surgery. ${ }^{9-11}$ However, these scores are not specific for patients undergoing $\mathrm{CABG}$ and, importantly, do not take into account preoperative antithrombotic regimens. The aim of this study was to develop a scoring method to stratify the risk of severe bleeding in patients undergoing $\mathrm{CABG}$ according to their baseline risk factors and antithrombotic treatment.

\section{Methods}

The E-CABG is an on-going European multicentre, prospective registry collecting data on patients undergoing $\mathrm{CABG}$ operated in 16 European centres of cardiac surgery in six European countries (England, Finland, France, Germany, Italy, Sweden). Twelve of these centres are university hospitals, two centres are central hospitals and two centres are private hospitals with agreements with the regional health authorities. This study was approved by the Institutional Review Board of the participating centers, and it was not financially supported. Informed consent was collected in Institutions where it was required by the internal Institutional Review Board, otherwise it was waived.

For the present analysis, the data were collected from January 1 to December 31, 2015. The ECABG study is registered in Clinicaltrials.gov (Identifier: NCT02319083) and its detailed protocol 
and definition criteria have been previously published. ${ }^{12}$ Of importance for this study, preoperative anemia was defined as hemoglobin level $<120 \mathrm{~g} / \mathrm{L}$ in women and $<130 \mathrm{~g} / \mathrm{L}$ in men. Estimated glomerular filtration rate was dichotomized according to a cut-off of $45 \mathrm{~mL} / \mathrm{min} / 1.73 \mathrm{~m}^{2}$, i.e. chronic kidney disease classes 1-3A vs. 3B-5, after univariate and multivariate analyses showed that this cutoff value had the largest impact on the severity of perioperative bleeding. Clopidogrel and ticagrelor were considered as potent antiplatelet drugs and potential triggers of excessive bleeding when discontinued less than five days. Although a pause of five days has been shown to be necessary for clopidogrel, a shorter pause is probably enough for ticagrelor. ${ }^{13}$ However, this issue is still controversial and for the sake of simplicity we used a pause of at least five days as a safe washout period for both these drugs. The use of low molecular weight heparin, fondaparinux and/or unfractionated heparin was considered as a single covariate and without taking into consideration their period of pause because of their pharmacologic characteristics and the fact that, when used, they are infrequently discontinued before surgery. Critical preoperative state was defined as any of the following conditions: ventricular tachycardia or ventricular fibrillation or aborted sudden death, preoperative cardiac massage, preoperative ventilation before anesthetic room, preoperative inotropes or intra-aortic balloon pump, preoperative acute renal failure (anuria or oliguria $<10 \mathrm{ml} / \mathrm{hr}$ ). Acute coronary syndrome was defined as any unstable angina, non-ST elevation or STelevation myocardial infarction requiring myocardial revascularization during the index hospitalization.

Data on baseline, intraoperative and postoperative variables were prospectively collected in an Access datasheet by researchers who were trained for data collection into this registry. Data were checked by researchers from each participating center before submitting dataset to the principal investigator for merging. External auditing of the data was not possible because of linguistic and geographical barriers. The principal investigator evaluated the databases for consistency by asking for missing and random data. 


\section{Outcomes}

The primary outcome of this analysis was severe bleeding as defined by the E-CABG bleeding grades 2-3, i.e. transfusion of more than four units of red blood cells and/or resternotomy for excessive bleeding. ${ }^{10}$ Secondary outcome measure of this study was in-hospital/30-day mortality.

\section{Statistical analysis}

Statistical analysis was performed using an SPSS statistical software (version 23.0, IBM Corporation; Armonk, New York, USA), SAS statistical software (version 9.4, SAS Institute Inc., Cary, NC, USA) and EasyROC online software (http://www.biosoft.hacettepe.edu.tr/easyROC/, accessed on October $\left.12^{\text {th }}, 2016\right)$. No attempt to replace missing values was made. Continuous variables were reported as the mean and standard deviation. Nominal variables were reported as counts and percentages. The Fisher's exact test, Chi-square test, Mann-Whitney test, Spearman test and Kruskal-Wallis tests were used for univariate analysis. Logistic regression with the backward stepwise entry method was employed to identify independent predictors of E-CABG grades 2-3 of perioperative bleeding. Only baseline covariates with $\mathrm{p}<0.2$ in univariate analysis were included in this regression model. The discriminatory ability of the regression model was assessed using the receiver operating characteristic (ROC) curve analysis. An additive risk score, the WILL-BLEED score, was developed by assigning a weighted integer to each independent risk factor on the basis of the coefficients of the final regression model using the Schneeweiss' method. ${ }^{14}$ A score for each patient was calculated by adding these weighted integers. Youden's test was used to identify the best cutoff of the WILL-BLEED score. ${ }^{15}$ The discriminatory ability of the WILL-BLEED score and of other bleeding risk scores (CRUSADE, ${ }^{7}$ ACTION, ${ }^{8}$ Papworth, ${ }^{9}$ TRUST $^{10}$ and TRACK ${ }^{11}$ bleeding risk scores, Suppl. Tab. 1) was evaluated by c-statistics. The DeLong test was used to determine if the difference between the area under the ROC curves (AUC) 
of these bleeding risk scores was statistically significant. ${ }^{16}$ Calibration of the risk scores was assessed by the Hosmer-Lemeshow's (HL) test. ${ }^{17}$

The improvement of discrimination of the WILL-BLEED score as compared to the other scores was estimated by calculating the net reclassification index (NRI) and integrated discrimination improvement (IDI). ${ }^{18}$ For the NRI, the risk categories were stratified into three groups of E-CABG bleeding grades $2-3$, i.e. $<5 \%, 5-11 \%,>11 \%$. A decision curve analysis ${ }^{19}$ was performed in order to estimate the clinical usefulness of each bleeding score. The decision curve analysis estimates the net benefit of a model by the difference between the number of true-positive and false-positive results, weighted by the odds of the selected threshold probability of risk. The net benefit of a model compared with the reference net benefit or with another model can be interpreted as the net increase in the proportion of cases identified. For any given threshold probability cutpoint, the risk model with the greatest net benefit would be the preferred model. Furthermore, the performance of the WILL-BLEED score was assessed by using it as an ordinal covariate and calculating the rates of severe bleeding for each category. Chi-squared automatic interaction detection (CHAID) analysis was performed to evaluate the interaction between the WILL-BLEED score and the impact of severity of perioperative bleeding on early postoperative mortality. The WILL-BLEED score was stratified in three categories of increasing severity (from 0 to 3, from 4 to 6 and higher than 6) and was forced as a first variable in to the CHAID regression model. All tests were two-sided with the alpha level set at 0.05 for statistical significance.

\section{Results}

Study population

Data was obtained from a series of 3788 consecutive patients who underwent isolated CABG. Patients treated with prasugrel $(n=43)$ and cangrelor $(n=1)$ were excluded from this analysis because no data on the timing of discontinuation of these drugs were collected. The final study population 
included 3744 patients and their rate of severe bleeding as defined by the E-CABG bleeding grades 2-3 was $6.4 \%(n=240)$. This population was divided after electronic random sampling into a derivation cohort $(n=2494,66.6 \%)$ and a validation cohort $(n=1250,33.4 \%)$. In the overall series, Baseline characteristics of patients of the derivation cohort were similar to those of the validation cohort (Tab. 1).

\section{Derivation and validation of the bleeding risk score}

Table 2 summarizes the baseline covariates associated with E-CABG bleeding grades 2-3 in univariate analysis of the derivation cohort. Logistic regression including baseline covariates with $\mathrm{p}<0.2$ in univariate analysis (HL test: $\mathrm{p}=0.100$, AUC of the ROC curve: $0.738,95 \%$ CI $0.692-0.784$ ) identified baseline anemia, female gender, eGFR $<45 \mathrm{~mL} / \mathrm{min} / 1.73 \mathrm{~m}^{2}$, potent antiplatelet drugs (clopidogrel and ticagrelor) discontinued less than five days, critical preoperative state, acute coronary syndrome as well as use of low molecular weight heparin, fondaparinux and/or unfractionated heparin as independent predictors of E-CABG bleeding grade 2-3 (Tab. 3). These variables were used to estimate the WILL-BLEED risk score by adding the weighted integers as listed in Table 3.

Severe bleeding defined as E-CABG bleeding grades 2-3 in both the derivation and validation cohorts was stratified according to the WILL-BLEED risk score (Fig. 1). The rate of severe bleeding increased across increasing scores in both the derivation and validation cohorts ( $p<0.0001)$. Youden's test showed that the best cutoff of this score was 5 (sensitivity $63.9 \%$, specificity $74.7 \%)$.

The WILL-BLEED score maintained its ability to predict severe bleeding according to the E-CABG bleeding classification $(\mathrm{p}<0.0001$, OR 1.393, 95\%CI 1.323-1.467) even when adjusted for participating centers.

The WILL-BLEED score correlated well with the observed bleeding, with increasing scores across 
increasing E-CABG grades of bleeding (Kruskal-Wallis test: $\mathrm{p}<0.0001$; Spearman test: rho: 0.304, p<0.0001) (Fig. 2).

Discrimination, calibration, reclassification and decision curve analysis of the WILL-BLEED score compared to other bleeding risk scores

In a series of 3621 patients with complete data to estimate all the following bleeding risk scores, ROC analysis showed an adequate discriminatory ability of the WILL-BLEED score (AUC 0.725, 95\%CI 0.686-0.763, HL test: $\mathrm{p}=0.033$ ) for prediction of E-CABG bleeding grades 2-3. The discriminatory ability for prediction of E-CABG bleeding grades 2-3 was lower for the ACTION (AUC 0.671, 95\%CI 0.631-0.710, HL test: $\mathrm{p}=0.469$, DeLong test: $\mathrm{p}=0.06$ ), CRUSADE (AUC 0.642, 95\%CI 0.602-0.681, HL test: $\mathrm{p}=0.016$, DeLong test: $\mathrm{p}=0.004$ ), Papworth (AUC 0.605, 95\%CI 0.568-0.643, HL test: $\mathrm{p}=0.028$, DeLong test: $\mathrm{p}=0.0001$ ), TRUST (AUC 0.660, 95\%CI 0.621-0.698, HL test: $\mathrm{p}=0.279$, DeLong test: $\mathrm{p}=0.02$ ) and TRACK (AUC 0.640, 95\%CI 0.6000.681, HL test: $\mathrm{p}=0.102$, DeLong test: $\mathrm{p}=0.004$ ) bleeding scores as compared with the WILLBLEED score. HL test for the WILL-BLEED score showed that this score underestimated the risk of severe bleeding in low risk patients. The HL test showed that the WILL-BLEED score had a $\mathrm{p}=0.408$ when patients with a score 0 to 1 were aggregated, and a $\mathrm{p}=0.679$ when patients with a score 0 were excluded from the analysis.

The NRI improvement using the WILL-BLEED score as opposed to the other bleeding scores was statistically significant $(\mathrm{p}<0.0001)$ with a correct reclassification of events ranging from $19 \%$ to $25 \%$ and a significant IDI ranging from $2.8 \%$ to $6.3 \%$ (p<0.0001) (Tab. 4 and Suppl. Tab. 2).

The decision curve analysis demonstrated a net benefit with the WILL-BLEED score compared to the other bleeding risk scores in predicting E-CABG grades 2-3 bleeding (Fig. 3).

The WILL-BLEED score and early mortality 
The WILL-BLEED score was predictive of early mortality (AUC: $0.782,95 \%$ CI $0.732-0.832$ ) and correlated with the EuroSCORE II (rho: 0.531, $\mathrm{p}<0.0001$ ). Youden's test showed that the best cutoff of the WILL-BLEED score in predicting early mortality was 4 (sensitivity $78.5 \%$, specificity $66.8 \%)$

CHAID analysis showed that the occurrence of E-CABG bleeding grades 2-3 was associated with significantly increased early mortality across increasing risk categories of the WILL-BLEED score (Fig. 4).

\section{Discussion}

This study showed that the WILL-BLEED score, based on a few baseline characteristics and antithrombotic treatment, allows an accurate stratification of the risk of perioperative bleeding across increasing grades of the E-CABG classification. Furthermore, this study showed that the WILL-BLEED score was predictive of early mortality and the risk of early death was increased by the occurrence of severe bleeding.

Severe bleeding is a common problem in patients undergoing cardiac surgery as it is associated with decreased oxygen delivery and need for blood transfusions, resulting in increased morbidity and mortality. This issue is of particular importance in patients undergoing $\mathrm{CABG}$, since urgent or emergency revascularization is often indicated in patients with acute coronary syndrome. In these patients, P2Y12 platelet receptor inhibitors, i.e., clopidogrel, prasugrel and ticagrelor, along with other antiplatelet and anticoagulant drugs are the cornerstone of treatment of acute coronary syndrome, albeit at the expense of a significantly increased risk of bleeding. ${ }^{20}$ Because of this, identification of patients at increased risk of bleeding after CABG may be of importance for optimization of antithrombotic therapy with the least risk of bleeding, ${ }^{20}$ when feasible. Indeed, this study confirmed that preoperative use of potent antiplatelet drugs and of parenteral anticoagulants were independent predictors of severe bleeding. On the other hand, modification of the 
antithrombotic regimen according to any risk stratification remains problematic because the most powerful baseline risk factors for ischemic complications are usually the same as for bleeding risk. $^{20}$ Importantly, most of the risk factors underlying an increased risk of bleeding are not modifiable. However, a number of bleeding-prevention and blood-saving strategies can be adopted in patients at high risk for hemorrhage. Vasques et al. ${ }^{21}$ summarized these strategies in three points: 1) preoperative optimization of hemoglobin ${ }^{22}$; 2) preoperative optimization of coagulation status by point-of-care coagulation testing ${ }^{23}$ and withdrawal of antithrombotics when feasible ${ }^{13}$; 3) minimization of intra- and postoperative blood loss by meticulous surgical technique, ${ }^{24}$ blood cell salvage and reinfusion, ${ }^{25}$ point-of-care coagulation tests, ${ }^{23}$ and administration of procoagulantss. ${ }^{26,27}$. These strategies have been shown to safely prevent significant blood loss and exposure to blood products in Jehovah's witnesses undergoing cardiac surgery, ${ }^{21}$ but are not used on daily basis. ${ }^{22}$ In this regard, identification of patients at high risk of bleeding by the WILLBLEED score may lead to optimization of patient blood management in these patients with a possible benefit for their early and late outcome. In fact, patients who experience severe postoperative bleeding defined as E-CABG bleeding grades 2-3 have been shown to be at high risk of early and late mortality. ${ }^{28}$

The WILL-BLEED score shares a number of risk factors for bleeding common to other bleeding risk scores derived from patients undergoing percutaneous coronary intervention and general cardiac surgery (Suppl. Tab. 1). Preoperative anemia defined by different thresholds of baseline hemoglobin ${ }^{8,29}$ and hematocrit ${ }^{7,10,11}$ is one of the most important components of the ACTION, CRUSADE, TRACK and TRUST risk scores. Although this finding is intuitive, since anemic patients require more frequently blood transfusions to maintain adequate levels of oxygen delivery, it is also possible that a decreased number of circulating erythrocytes may impair coagulation. In fact, there is a growing body of evidence showing that erythrocytes have an active role in hemostasis by enhancing platelet aggregation and degranulation and serve as a procoagulant surface 
for the reactions of the coagulation cascade. ${ }^{30}$ These findings suggest that optimization of preoperative hemoglobin could be one of the most important interventions in the patient blood management process.

Renal failure is a well-recognized risk factor for perioperative bleeding, ${ }^{31}$ and is a common component of current bleeding risk scores. ${ }^{6,7,8,10,29}$ Among the risk scores herein validated, the ACTION, CRUSADE and TRUST score shared this risk factor. The impact of chronic kidney disease on bleeding is partly due to the prolonged half-life of certain antithrombotics in patients with renal failure. ${ }^{32}$ However, renal failure by itself has a profound impact on the coagulation pathway, which may induce either pronounced bleeding or thrombosis. Regarding the uremiarelated risk of bleeding, it seems to be secondary to insufficient platelet function, reduced interaction between platelets and vessel wall as well as anemia-related coagulopathy. ${ }^{32}$ Although chronic kidney disease is a non-modifiable risk factor in patients undergoing cardiac surgery, knowledge of their increased risk of bleeding may guide strategies to improve the coagulation status of uremic patients by avoiding or reducing the dose of certain antithrombotics and adopt more strict measures to avoid blood loss perioperatively. It is worth noting that in the present study we stratified the severity of renal failure according to eGFR values, which may be more accurate than simply evaluating baseline creatinine levels of these patients.

Female gender is associated with a higher risk of bleeding after cardiovascular intervention as shown in several trials, ${ }^{33}$ and is a constant component of most of risk bleeding scores ${ }^{5-8,10,11}$ Among the risk scores herein validated, the ACTION, CRUSADE, TRACK and TRUST scores included female gender as a risk factor for increased bleeding. The higher risk of bleeding among women was confirmed also in this study. Although women's vessel anatomy, body mass index and hemoglobin levels may result in possible unfavorable differences during cardiovascular interventions, the increased risk of bleeding among females may be related to peculiar differences in the coagulation process between genders. In fact, even when adjusted for important baseline risk 
factors, women undergoing percutaneous coronary intervention have been shown to have a higher risk of both ischemic and bleeding events. ${ }^{33}$ In the present study, we were not able to confirm the prognostic importance of advanced age and decreased body mass index/weight on the risk of severe perioperative bleeding as observed in previous studies. ${ }^{9,10,11,29}$ These variables were investigated as continuous as well as dichotomous covariates according to previously proposed cutoff values, but analyses failed to confirm their impact on severe bleeding as observed also in the CRUSADE study. ${ }^{7}$ On the other hand, advanced age and low body mass index were associated with increasing postoperative bleeding across increasing severity grades of the E-CABG bleeding classification (both variables, Kruskall-Wallis test: $\mathrm{p}<0.0001$ ). However, severe bleeding is the one which showed being of most prognostic significance in patients undergoing $\mathrm{CABG}{ }^{28}$

Comparative analysis of the AUCs of the WILL-BLEED score with the other bleeding risk scores showed that the former score had a significantly better discriminatory ability than the CRUSADE, Papworth, TRUST and TRACK bleeding risk scores. Such a difference tended to be statistically significant also for the ACTION score ( $\mathrm{p}=0.07)$. NRI, IDI and decision curve analysis confirmed the that the WILL-BLEED score had a better performance in predicting severe bleeding. It is worth noting that the calibration for this score was not optimal. In fact, the HL test showed that the WILLBLEED score underestimated the risk of severe bleeding in low risk patients. This could be due to unexpected excessive bleeding in low risk patients related to a non-meticulous surgical technique. The HL test showed that the WILL-BLEED score had a $\mathrm{p}=0.408$ when patients with a score 0 to 1 were aggregated, and a $\mathrm{p}=0.679$ when patients with a score 0 were excluded from the analysis. The use of a tool for stratification of the risk of postoperative bleeding such as the WILL-BLEED score has a number of research and clinical implications. This scoring method allows a preoperative estimation of the risk of bleeding which is of value for comparative analysis of the benefits and harms of using antithrombotics and procoagulants in patients with either stable angina or acute coronary syndrome. Estimation of the risk of bleeding may be useful also in comparative analyses 
of the efficacy of point-of-care bleeding management and blood conservation strategies.

Furthermore, it may provide a valid measure for the evaluation of individual surgeon and interinstitutional variability of perioperative bleeding and requirement of blood products. Regarding the clinical implications of this scoring method, Figure 5 shows an algorithm which summarizes the risk factors for severe bleeding, their increasing impact on perioperative bleeding and the measures to be adopted in order to reduce blood loss and the need of blood transfusion. Most of the components of this risk score are not modifiable and a direct action is feasible only on preoperative anemia and antithrombotic treatment. However, even when feasible, preoperative optimization of hemoglobin and discontinuation of antithrombotics should be carefully considered according to the specific clinical conditions in view of their potential harms. However, recognizing the clinical importance of excessive perioperative bleeding, the WILL-BLEED score easily provides an estimation of the risk of severe bleeding and may guide surgeons and anesthesiologists to adopt adequate measures to prevent bleeding at least in high risk patients. The central role of surgeon in preventing intra- and postoperative bleeding cannot be overemphasized. ${ }^{24}$ A pooled analysis showed that diffuse bleeding (diffuse ooze, no surgical cause identified) was found at re-exploration in only $21 \%$ of cases. ${ }^{35}$ This finding confirm the "surgical nature" of most of severe hemorrhages and confirms the importance of a meticulous surgical technique as one of the most important measure to prevent blood loss. Importantly, the "surgical nature" of bleeding after CABG and a possible inter-individual variability among surgeons may explain the suboptimal goodness-of-fit of the WILL-BLEED score, which was due to an underestimation of the bleeding risk in low risk patients. Indeed, CABG in low risk patients is often performed by less experienced surgeons. This may expose these patients to longer operation time, which increases the period of intraoperative bleeding and the risk of cardiopulmonary bypass-related coagulopathy and suboptimal surgical hemostasis. In general, the prognostic impact of a non-meticulous surgical technique is not 
quantifiable and may be responsible for the excessive bleeding still sporadically occurring in low risk patients.

Another key issue in preventing bleeding in patients undergoing cardiac surgery is the adoption of point-of-care coagulation testing and an integrated transfusion algorithm, which has been shown to effectively guide clinicians in reducing blood loss and transfusion. ${ }^{36}$ These measures could be of benefit particularly in patients with high WILL-BLEED score.

Several limitations of the present study should be considered. This is a multicenter study involving 16 centers of cardiac surgery with possible differences in terms of referral pathways, operative risk, antithrombotic treatments and patient blood management strategies. However, analysis adjusted for the participating centers showed that the WILL-BLEED score maintained its ability to predict severe bleeding. Furthermore, this registry does not collect data on individual surgeons and this represents another limitation of this study, particularly in view of the recognized surgeon's impact on the risk of excessive bleeding. ${ }^{24}$ On the other hand, the multicenter nature of this registry and the large number of surgeons who operated these patients would prevent a reliable analysis of this issue.

In conclusion, The WILL-BLEED risk score seems to be a simple tool to identify patients at high risk of severe bleeding after isolated CABG. The present findings as well as those of previous studies suggest that stratification of the risk of bleeding in patients undergoing cardiovascular intervention is feasible. This could be a valid means for prevention of excessive blood loss and exposure to blood products in patients undergoing cardiovascular procedures.

\section{Conflicts of interest: None}

\section{References}


1. Habib RH, Zacharias A, Schwann TA, et al. Adverse effects of low hematocrit during cardiopulmonary bypass in the adult: should current practice be changed? $\mathrm{J}$ Thorac Cardiovasc Surg. 2003-;125:1438-1450.

2. Eikelboom JW, Mehta SR, Anand SS, et al. Adverse impact of bleeding on prognosis in patients with acute coronary syndromes. Circulation 2006;114:774-782.

3. Rao SV, O'Grady K, Pieper KS, et al. Impact of bleeding severity on clinical outcomes among patients with acute coronary syndromes. Am J Cardiol 2005;96:1200-1206.

4. Manoukian SV, Feit F, Mehran R, et al. Impact of major bleeding on 30-day mortality and clinical outcomes in patients with acute coronary syndromes. An analysis from the ACUITY trial. J Am Coll Cardiol 2007;49:1362-1368.

5. Mehta SK, Frutkin AD, Lindsey JB, et al. Bleeding in patients undergoing percutaneous coronary interv-ention: the development of a clinical risk algorithm from the national cardiovascular data registry. Circ Cardiovasc Interv. 2009;2:222-229.

6. Mehran R, Pocock SJ, Nikolsky E, et al. A risk score to predict bleeding in patients with acute coronary syndromes. J Am Coll Cardiol 2010;55:2556-2566.

7. Subherwal S, Bach RG, Chen AY, et al. Baseline risk of major bleeding in non-ST-segmentelevation myocardial infarction. The CRUSADE (Can Rapid risk stratification of Unstable angina patients Suppress ADverse outcomes with Early implementation of the ACC/AHA guidelines) bleeding score. Circulation 2009;119:1873-1882.

8. Mathews R, Peterson ED, Chen AY, et al. In-hospital major bleeding during ST-elevation and non-ST-elevation myocardial infarction care: derivation and validation of a model from the ACTION Registry®-GWTGTM . Am J Cardiol 2011;107:1136-1143.

9. Vuylsteke A, Pagel C, Gerrard C, et al. The Papworth Bleeding Risk Score: a stratification scheme for identifying cardiac surgery patients at risk of excessive early postoperative bleeding. Eur J Cardiothorac Surg 2011;39:924-931. 
10. Alghamdi AA, Davis A, Brister S, et al. Development and validation of Transfusion Risk Understanding Scoring Tool (TRUST) to stratify cardiac surgery patients according to their blood transfusion needs. Transfusion 2006;46:1120-1129.

11. Ranucci M, Castelvecchio S, Frigiola A, et al. Predicting transfusions in cardiac surgery: the easier, the better: the Transfusion Risk and Clinical Knowledge score. Vox Sang 2009;96:324-332. 12. Biancari F, Ruggieri VG, Perrotti A, et al. European multicenter study on coronary artery bypass grafting (E-CABG registry): study protocol for a prospective clinical registry and proposal of classification of postoperative complications. J Cardiothorac Surg 2015;10:90.

13. Hansson EC, Jidéus L, Åberg B, et al. Coronary artery bypass grafting-related bleeding complications in patients treated with ticagrelor or clopidogrel: a nationwide study. Eur Heart $\mathbf{J}$ 2016;37:189-197.

14. Schneeweiss S, Wang PS, Avorn J, et al. Improved comorbidity adjustment for predicting mortality in Medicare populations. Health Serv Res 2003;38:1103-1120.

15. Youden WJ. Index for rating diagnostic tests. Cancer 1950;3:32-5.

16. DeLong ER, DeLong DM, Clarke-Pearson DL. Comparing the areas under two or more correlated receiver operating characteristic curves: a nonparametric approach. Biometrics 1988;44:837-845.

17. Hosmer DW, Lemeshow S. A goodness-of-fitness test for the multiple logistic regression model. Comm Stat 1980;A10:1043-1069.

18. Pencina MJ, D'Agostino RB Sr, D'Agostino RB Jr, Vasan RS. Evaluating the added predictive ability of a new marker: from area under the ROC curve to reclassification and beyond. Stat Med. 2008;27:157-72.

19. Vickers AJ, Elkin EB. Decision curve analysis: a novel method for evaluating prediction models. Med Decis Making 2006;26:565-574. 
20. Bhatt DL, Hulot JS, Moliterno DJ, et al. Antiplatelet and anticoagulation therapy for acute coronary syndromes. Circ Res 2014;114:1929-1943.

21. Vasques F, Kinnunen EM, Pol M, et al. Outcome of Jehovah's Witnesses after adult cardiac surgery: systematic review and meta-analysis of comparative studies. Transfusion 2016;56:21462153.

22. D'Ambra MN, FitzGerald D, Kaufman RM, et al. Blood conservation: why aren't we doing this for everyone? J Thorac Cardiovasc Surg 2015;150:984-985.

23. Deppe AC, Weber C, Zimmermann J, et al. Point-of-care thromboelastography/thromboelastometry-based coagulation management in cardiac surgery: a meta-analysis of 8332 patients. J Surg Res 2016;203:424-433.

24. Biancari F, Mikkola R, Heikkinen J, et al. Individual surgeon's impact on the risk of reexploration for excessive bleeding after coronary artery bypass surgery. J Cardiothorac Vasc Anesth 2012;26:550-556.

25. Vonk AB, Meesters MI, Garnier RP, et al. Intraoperative cell salvage is associated with reduced postoperative blood loss and transfusion requirements in cardiac surgery: a cohort study. Transfusion 2013;53:2782-2789.

26. Ranucci M, Baryshnikova E, Crapelli GB, et al. Randomized, double-blinded, placebocontrolled trial of fibrinogen concentrate supplementation after complex cardiac surgery. J Am Heart Assoc 2015;4:e002066.

27. Ortmann E, Besser MW, Sharples LD, et al. An exploratory cohort study comparing prothrombin complex concentrate and fresh frozen plasma for the treatment of coagulopathy after complex cardiac surgery. Anesth Analg 2015;121:26-33.

28. Kinnunen EM, Mosorin MA, Perrotti A, et al. Validation of a new classification method of postoperative complications in patients undergoing coronary artery surgery. J Cardiothorac Vasc Anesth 2016;30:330-337. 
29. Rao SV, McCoy LA, Spertus JA, et al. An updated bleeding model to predict the risk of postprocedure bleeding among patients undergoing percutaneous coronary intervention: a report using an expanded bleeding definition from the National Cardiovascular Data Registry CathPCI Registry. JACC Cardiovasc Interv 2013;6:897-904.

30. Du VX, Huskens D, Maas C, et al. New insights into the role of erythrocytes in thrombus formation. Semin Thromb Hemost 2014;40:72-80.

31. Acedillo RR, Shah M, Devereaux PJ, et al. The risk of perioperative bleeding in patients with chronic kidney disease: a systematic review and meta-analysis. Ann Surg 2013;258:901-913.

32. Lutz J, Menke J, Sollinger D, et al. Haemostasis in chronic kidney disease. Nephrol Dial Transplant 2014;29:29-40.

33. Ahmed B, Dauerman HL. Women, bleeding, and coronary intervention. Circulation 2013;127:641-649.

34. Davidson S. State of the art - how I manage coagulopathy in cardiac surgery patients. Br J Haematol 2014;164:779-789.

35. Biancari F, Mikkola R, Heikkinen J, Lahtinen J, Airaksinen KE, Juvonen T. Estimating the risk of complications related to re-exploration for bleeding after adult cardiac surgery: a systematic review and meta-analysis. Eur J Cardiothorac Surg 2012;41:50-55.

36. Karkouti K, Callum J, Wijeysundera DN, et al. Point-of-care hemostatic testing in cardiac surgery: a stepped-wedge clustered randomized controlled trial. Circulation 2016 (in press) 


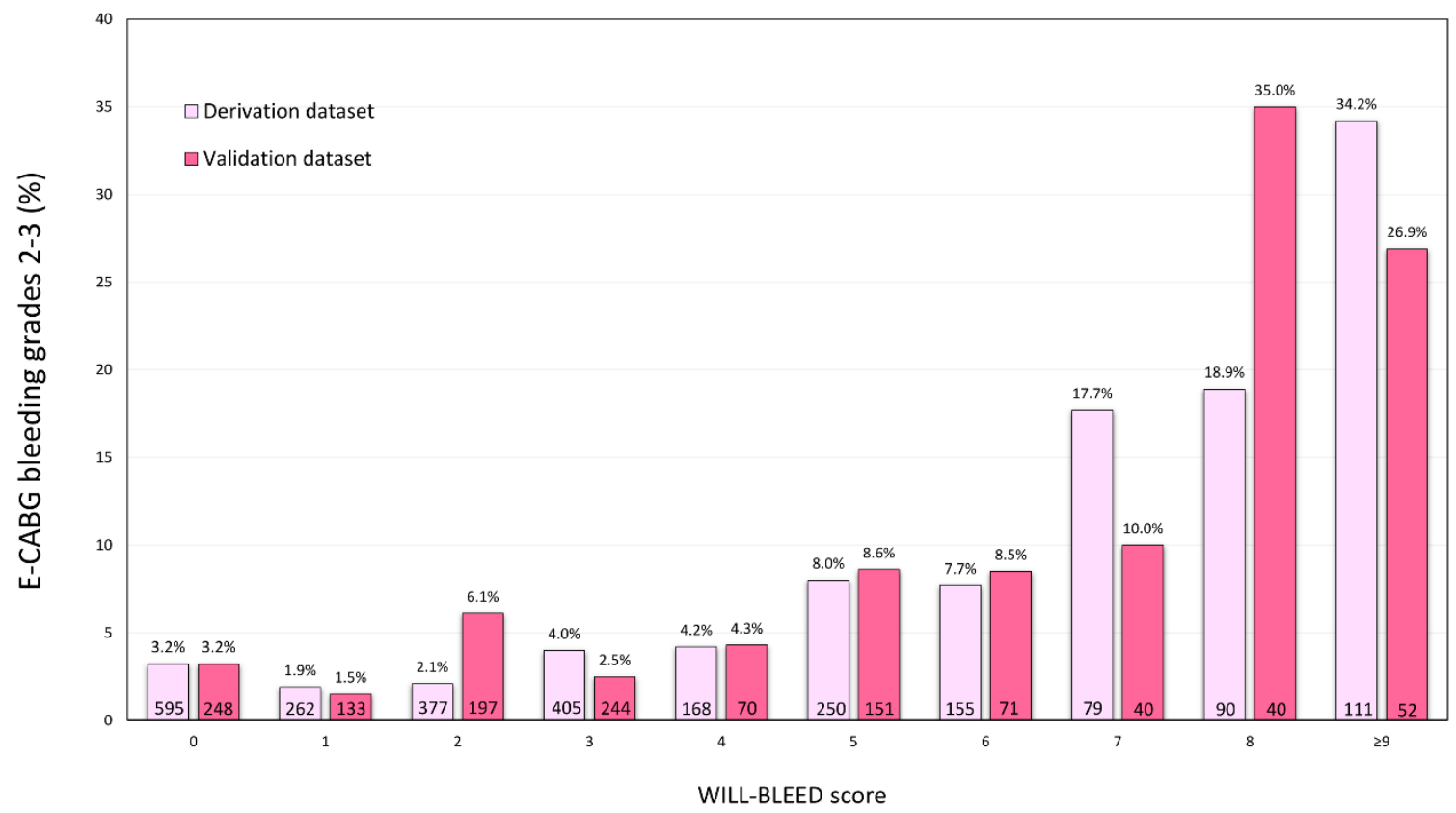

Figure 1. Rates of severe bleeding defined as E-CABG bleeding grades 2-3 in the derivation and validation cohorts according to the WILL-BLEED risk score. 


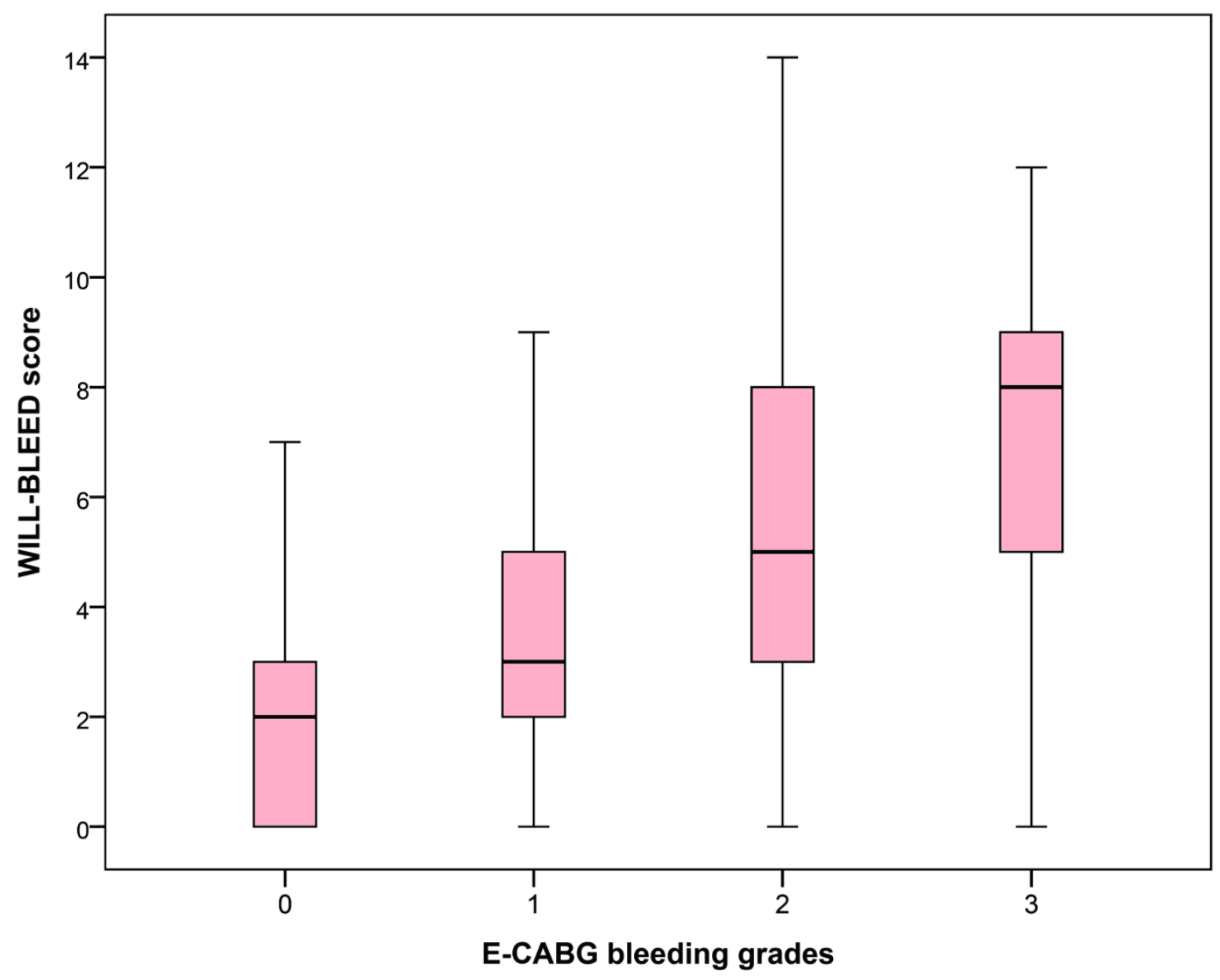

Figure 2. Boxplots of the WILL-BLEED score across increasing E-CABG bleeding grades (Kruskal-Wallis' test: $\mathrm{p}<0.0001)$. 


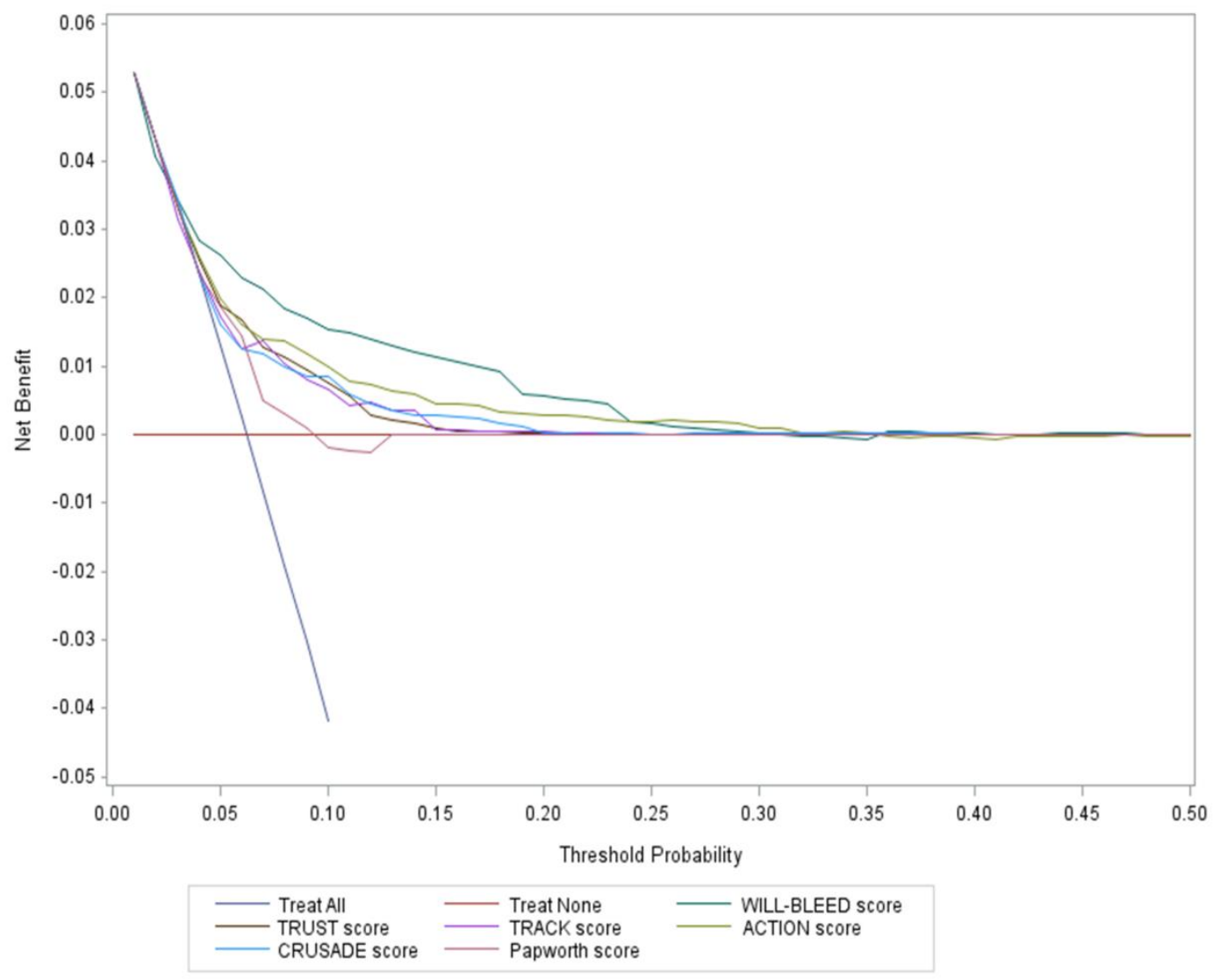

Figure 3. Decision curves for the predicted probabilities of E-CABG grade 2-3 bleeding estimated by the WILL-BLEED, ACTION, CRUSADE, TRACK, TRUST and Papworth bleeding scores. 


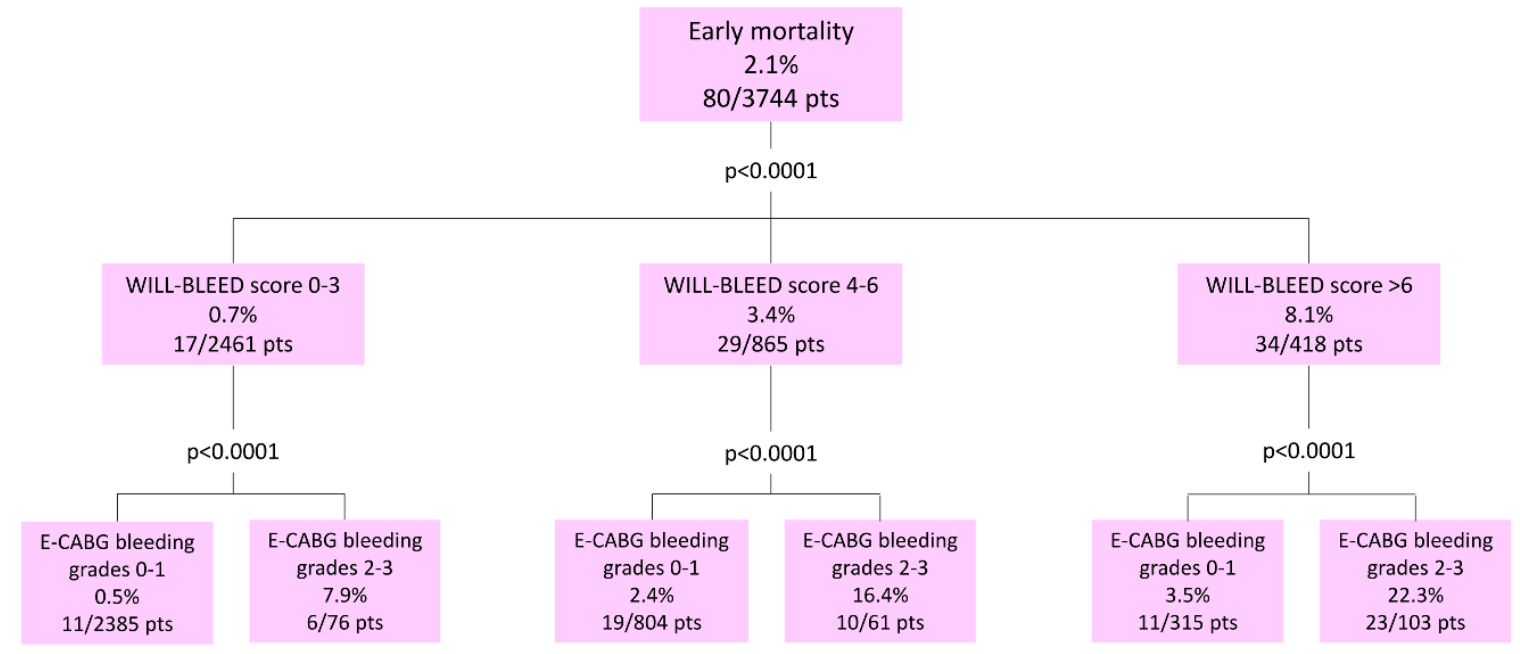

Figure 4. Chi-squared automatic interaction detection analysis showing the impact of severity of bleeding (E-CABG bleeding grades 0-1 vs 2-3) on 30-day mortality in different WILL-BLEED score classes. 


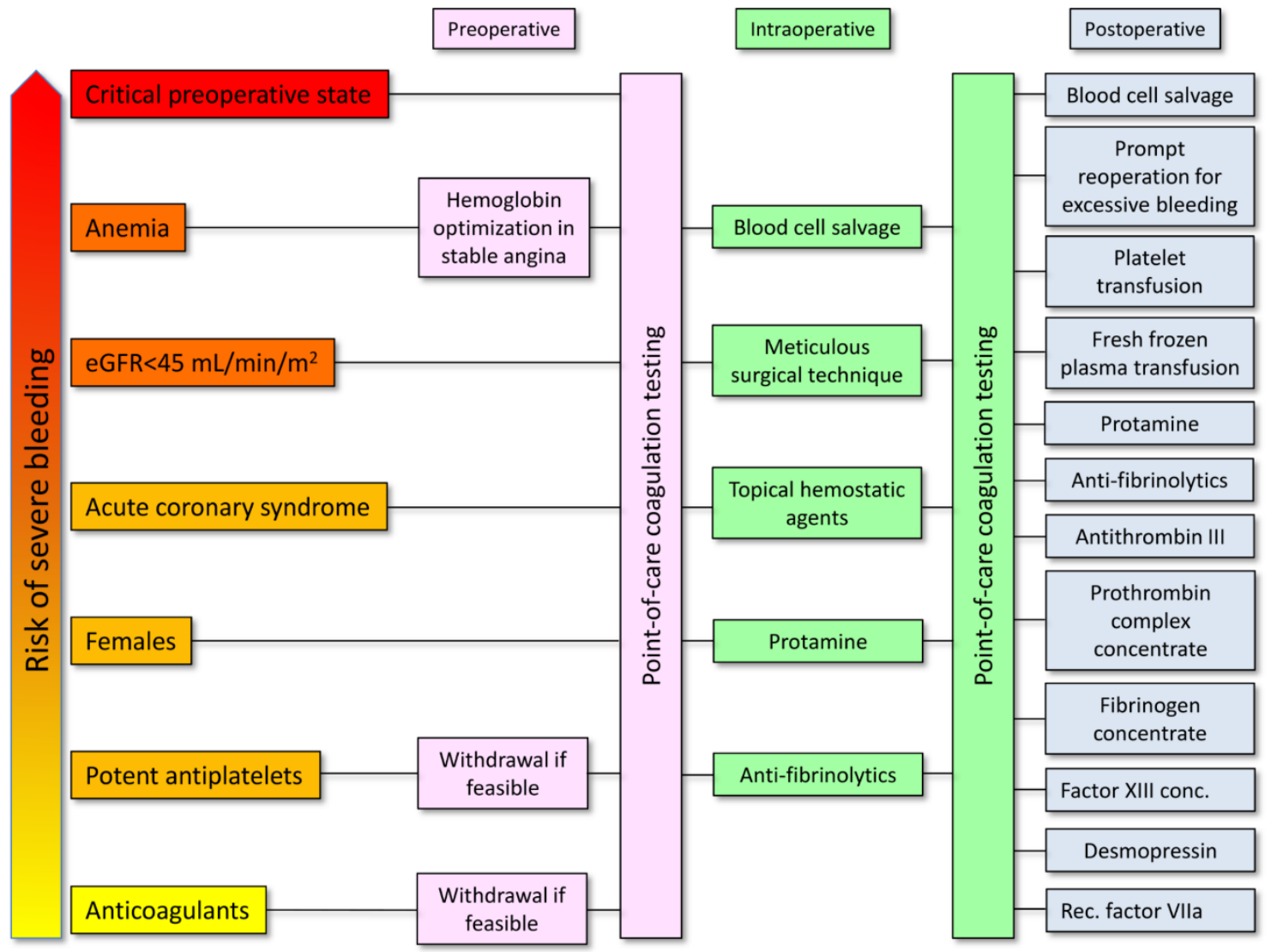

Figure 5. Algorithm of risk estimation and prevention of severe bleeding in coronary surgery. 


\section{Extra table}

1. What is known on this topic

- Severe perioperative bleeding is associated with poor outcome after cardiac surgery

- The use of potent antithrombotics may add a significant risk of bleeding in patients undergoing coronary surgery

- There are no specific risk scoring methods to stratify the risk of bleeding after coronary surgery

2. What this paper adds

- The WILL-BLEED score is a rather accurate method to predict severe bleeding after coronary surgery

- The WILL-BLEED is made up of seven easily retrievable clinical variables which make easy its use at bed-side

- The WILL-BLEED may be useful to improve patient-blood management in patients at high risk of perioperative bleeding 
Table 1. Baseline characteristics and operative data of the derivation and validation cohorts.

\begin{tabular}{|c|c|c|c|}
\hline Covariates & $\begin{array}{l}\text { Derivation } \\
(n=2494)\end{array}$ & $\begin{array}{l}\text { Validation } \\
(n=1250)\end{array}$ & $P$-value \\
\hline Age, years & $67.3 \pm 9.4$ & $67.4 \pm 9.2$ & 0.710 \\
\hline Females & $409(16.4)$ & $219(17.5)$ & 0.404 \\
\hline $\mathrm{BMI}>25 \mathrm{~kg} / \mathrm{m}^{2}$ & $718(29.0)$ & $360(29.0)$ & 1.000 \\
\hline Hemoglobin, g/dL & $136.2 \pm 16.5$ & $135.9 \pm 16.4$ & 0.354 \\
\hline Anemia & $564(22.6)$ & $294(23.5)$ & 0.536 \\
\hline Platelets, g/dL & $227.1 \pm 67.7$ & $226.5 \pm 68.0$ & 0.577 \\
\hline TT-INR & $1.1 \pm 0.2$ & $1.1 \pm 0.2$ & 0.433 \\
\hline $\mathrm{eGFR} \mathrm{mL} / \mathrm{min} / 1.73 \mathrm{~m}^{2}$ & $81.2 \pm 25.8$ & $80.1 \pm 25.8$ & 0.046 \\
\hline Hypertension & $1959(78.5)$ & $1017(81.4)$ & 0.048 \\
\hline Diabetes on medical treatment & $762(30.6)$ & $438(35.1)$ & 0.006 \\
\hline Extracardiac arteriopathy & $502(20.1)$ & $276(22.1)$ & 0.172 \\
\hline Stroke & $93(3.7)$ & $52(4.2)$ & 0.530 \\
\hline Chronic lung disease & $232(9.3)$ & $115(9.2)$ & 0.952 \\
\hline Atrial fibrillation & $192(7.7)$ & $99(8.0)$ & 0.796 \\
\hline \multicolumn{4}{|l|}{ LVEF classes } \\
\hline $31-50 \%$ & $591(23.7)$ & $299(24.0)$ & 0.742 \\
\hline $21-30 \%$ & $106(4.3)$ & $56(4.5)$ & 0.724 \\
\hline$<21 \%$ & $17(0.7)$ & $5(0.4)$ & 0.937 \\
\hline Prior cardiac surgery & $22(0.9)$ & $9(0.7)$ & 0.704 \\
\hline Prior PCI & $531(21.3)$ & $269(21.5)$ & 0.866 \\
\hline Number of prior PCIs & $1.5 \pm 0.9$ & $1.4 \pm 0.8$ & 0.519 \\
\hline Left main stenosis & $933(37.4)$ & $436(35.0)$ & 0.150 \\
\hline Syntax score & $28.1 \pm 11.1$ & $28.5 \pm 10.4$ & 0.118 \\
\hline No. of diseased vessels & $2.7 \pm 0.6$ & $2.7 \pm 0.6$ & 0.747 \\
\hline Acute coronary syndrome & $1174(47.0)$ & $602(48.2)$ & 0.532 \\
\hline Recent myocardial infarction & $750(30.1)$ & $386(30.9)$ & 0.624 \\
\hline Urgent or emergency surgery & $1099(44.1)$ & $547(43.8)$ & 0.862 \\
\hline Critical preoperative state & $96(3.8)$ & $42(3.4)$ & 0.520 \\
\hline \multicolumn{4}{|l|}{ Antithrombotic treatment } \\
\hline Potent antiplatelet pause $<5$ days & $342(13.7)$ & $174(13.9)$ & 0.880 \\
\hline Warfarin/coumadin/phenprocoumon & $51(2.0)$ & $36(2.9)$ & 0.134 \\
\hline Glycoprotein $2 \mathrm{~b} / 3 \mathrm{a}$ inhibitors & $23(0.9)$ & $22(1.8)$ & 0.037 \\
\hline LMWH/fondaparinux/unfract. heparin & $1048(42.0)$ & $548(43.8)$ & 0.293 \\
\hline Off-pump surgery & $509(20.4)$ & $262(21.0)$ & 0.700 \\
\hline No. of distal anastomoses & $2.7 \pm 1.1$ & $2.7 \pm 0.9$ & 0.483 \\
\hline EuroSCORE II & $2.6 \pm 4.0$ & $2.6 \pm 3.7$ & 0.525 \\
\hline
\end{tabular}

TT-INR, thromboplastin time - international normalized ratio; eGFR, estimated glomerular filtration rate; MDRD, Modification of Diet in Renal Disease; BMI, Body mass index; LMWH, low molecular weight heparin; LVEF, left ventricle ejection fraction; PCI, percutaneous coronary intervention; CABG, coronary artery bypass grafting. 
Table 2. Baseline characteristics and operative data in patients of the derivation cohort who experienced or not severe bleeding defined as E-CABG bleeding grades 2-3.

\begin{tabular}{|c|c|c|c|}
\hline Covariates & $\begin{array}{c}E-C A B G \text { bleeding } \\
\text { grades } 0-1 \\
(n=2336)\end{array}$ & $\begin{array}{c}E-C A B G \text { bleeding } \\
\text { grades } 2-3 \\
(n=156)\end{array}$ & $\begin{array}{c}\text { Univariate analysis } \\
\qquad P \text {-value }\end{array}$ \\
\hline Age, years & $67.2 \pm 9.4$ & $68.1 \pm 9.4$ & 0.200 \\
\hline Females & $364(15.6)$ & $45(28.5)$ & $<0.0001$ \\
\hline $\mathrm{BMI}>25 \mathrm{~kg} / \mathrm{m}^{2}$ & $27.5 \pm 4.2$ & $27.3 \pm 4.6$ & 0.396 \\
\hline Hemoglobin, g/dL & $137 \pm 16$ & $126 \pm 21$ & $<0.0001$ \\
\hline Anemia & $489(20.9)$ & $75(47.8)$ & $<0.0001$ \\
\hline Platelets, g/dL & $227 \pm 65$ & $227 \pm 97$ & 0.264 \\
\hline TT-INR & $1.1 \pm 0.2$ & $1.1 \pm 0.2$ & 0.001 \\
\hline $\mathrm{eGFR}, \mathrm{mL} / \mathrm{min} / 1.73 \mathrm{~m}^{2}$ & $82 \pm 25$ & $72 \pm 31$ & $<0.0001$ \\
\hline Number of prior PCIs & $1.5 \pm 0.8$ & $1.7 \pm 1.3$ & 0.376 \\
\hline Extracardiac arteriopathy & 464 (19.9) & $38(24.1)$ & 0.204 \\
\hline Stroke & $88(3.8)$ & $5(3.2)$ & 1.000 \\
\hline Diabetes on medical treatment & $709(30.4)$ & $53(33.5)$ & 0.401 \\
\hline Hypertension & $1836(78.6)$ & $123(77.8)$ & 0.825 \\
\hline Chronic lung disease & $210(9.0)$ & $22(13.9)$ & 0.039 \\
\hline Atrial fibrillation & $171(7.3)$ & $21(13.3)$ & 0.007 \\
\hline LVEF classes & & & $<0.0001$ \\
\hline $31-50 \%$ & $542(23.2)$ & $49(31.0)$ & \\
\hline $21-30 \%$ & $93(4.0)$ & $13(8.2)$ & \\
\hline$<21 \%$ & $12(0.5)$ & $5(3.2)$ & \\
\hline Prior cardiac surgery & $19(0.8)$ & $3(1.9)$ & 0.159 \\
\hline Prior PCI & $497(21.3)$ & $34(21.5)$ & 0.942 \\
\hline Left main stenosis & $867(37.1)$ & $66(41.8)$ & 0.242 \\
\hline Syntax score & $28.0 \pm 11.1$ & $29.6 \pm 10.6$ & 0.057 \\
\hline No. of diseased vessels & $2.7 \pm 0.6$ & $2.7 \pm 0.5$ & 0.357 \\
\hline Acute coronary syndrome & $1063(45.5)$ & $110(69.6)$ & $<0.0001$ \\
\hline Recent myocardial infarction & $671(28.7)$ & $79(50.0)$ & $<0.0001$ \\
\hline Urgent or Emergency & 995 (42.6) & $104(65.8)$ & $<0.0001$ \\
\hline Critical preoperative state & $67(2.9)$ & $29(18.4)$ & $<0.0001$ \\
\hline \multicolumn{4}{|l|}{ Antithrombotic treatment } \\
\hline Warfarin/coumadin/phenprocoumon & $46(2.0)$ & $5(3.2)$ & 0.253 \\
\hline Glycoprotein $2 \mathrm{~b} / 3 \mathrm{a}$ inhibitors & $2(0.9)$ & $1(0.6)$ & 1.000 \\
\hline LMWH/fondaparinux/UFH & $960(41.1)$ & $88(55.7)$ & $<0.0001$ \\
\hline Potent antiplatelet pause $<5$ days & $304(13.0)$ & $38(24.1)$ & $<0.0001$ \\
\hline Off pump surgery & $418(20.6)$ & $28(17.7)$ & 0.386 \\
\hline No. of distal anastomoses & $2.7 \pm 1.0$ & $2.7 \pm 0.9$ & 0.508 \\
\hline EuroSCORE II & $2.4 \pm 3.3$ & $6.0 \pm 8.6$ & $<0.0001$ \\
\hline
\end{tabular}

TT-INR, thromboplastin time - international normalized ratio; BMI, body mass index; eGFR, estimated glomerular filtration rate; LMWH, low molecular weight heparin; UFH, unfractionated heparin; LVEF, left ventricular ejection fraction; PCI, percutaneous coronary intervention; 
Table 3. Independent predictors of E-CABG bleeding grades 2-3 in the derivation cohort and their weighted integer scores.

\begin{tabular}{lccccc}
\hline \multicolumn{1}{c}{ Covariate } & Beta & p-value & OR & 95\%CI & Score \\
\hline LMWH/ fondaparinux/UFH & 0.376 & 0.035 & 1.456 & $1.027-2.064$ & 1 \\
Potent antiplatelet drugs & 0.514 & 0.016 & 1.671 & $1.100-2.539$ & 2 \\
pause <5 days & & & & $1.140-2.485$ & 2 \\
Females & 0.521 & 0.009 & 1.683 & $1.106-2.374$ & 2 \\
Acute coronary syndrome & 0.483 & 0.013 & 1.621 & $1.768-3.591$ & 3 \\
Anemia & 0.924 & $<0.0001$ & 2.520 & $1.587-4.033$ & 3 \\
eGFR <45 mL/min/1.73m ${ }^{2}$ & 0.928 & $<0.0001$ & 2.530 & $2.846-8.034$ & 5 \\
Critical preoperative state & 1.565 & $<0.0001$ & 4.782 & & \\
Constant & -3.916 & $<0.0001$ & & & \\
\hline
\end{tabular}

OR: odds ratio; CI: confidence interval; LMWH, low molecular weight heparin; UFH, unfractionated heparin; eGFR, estimated glomerular filtration rate. 
Table 4. Net reclassification index and integrated discrimination improvement between the WILLBLEED score other bleeding risk scores in predicting E-CABG bleeding grades 2-3.

\begin{tabular}{llllllll}
\hline $\begin{array}{l}\text { Bleeding } \\
\text { scores }\end{array}$ & \multicolumn{9}{c}{ NRI } & \multicolumn{3}{c}{ IDI } & \\
& NRI & $95 \%$ CI & p-value & $\begin{array}{l}\text { Correctly } \\
\text { reclassified }\end{array}$ & IDI & $95 \%$ CI & p-value \\
\hline ACTION & 0.518 & $0.388-0.649$ & $<0.0001$ & $23 \%$ & 0.028 & $0.017-0.039$ & $<0.0001$ \\
CRUSADE & 0.493 & $0.362-0.625$ & $<0.0001$ & $21 \%$ & 0.046 & $0.035-0.058$ & $<0.0001$ \\
TRACK & 0.491 & $0.358-0.622$ & $<0.0001$ & $19 \%$ & 0.049 & $0.037-0.061$ & $<0.0001$ \\
TRUST & 0.567 & $0.437-0.697$ & $<0.0001$ & $25 \%$ & 0.046 & $0.034-0.057$ & $<0.0001$ \\
Papworth & 0.762 & $0.632-0.891$ & $<0.0001$ & $25 \%$ & 0.063 & $0.049-0.077$ & $<0.0001$ \\
\hline
\end{tabular}

NRI, net reclassification index; IDI, integrated discrimination improvement; CI: confidence interval. 


\section{Supplemental material}

\section{Prediction of Severe Bleeding after Coronary Surgery: the WILL-BLEED Risk Score}

Supplemental Table 1. Bleeding risk scores evaluated in this analysis.

\begin{tabular}{|c|c|c|c|c|c|c|c|c|c|}
\hline \multicolumn{10}{|c|}{ WILL-BLEED bleeding score } \\
\hline \multicolumn{5}{|l|}{ Variable } & \multicolumn{5}{|l|}{ Score } \\
\hline \multicolumn{5}{|c|}{ LMWH/ fondaparinux/unfractionated heparin } & 1 & & & & \\
\hline \multicolumn{5}{|c|}{ Potent antiplatelet drugs pause $<5$ days } & 2 & & & & \\
\hline \multicolumn{5}{|l|}{ Females } & 2 & & & & \\
\hline \multicolumn{5}{|c|}{ Acute coronary syndrome } & 2 & & & & \\
\hline \multicolumn{5}{|l|}{ Anemia } & 3 & & & & \\
\hline \multicolumn{5}{|c|}{$\mathrm{eGFR}<45 \mathrm{~mL} / \mathrm{min} / 1.73 \mathrm{~m}^{2}$} & 3 & & & & \\
\hline \multicolumn{5}{|c|}{ Critical preoperative state } & 5 & & & & \\
\hline \multicolumn{10}{|c|}{ ACTION bleeding score } \\
\hline Age (years) & Score & $\begin{array}{l}\text { Baseline } \\
\text { creatinine } \\
(\mathrm{mg} / \mathrm{dl})\end{array}$ & Score & $\begin{array}{c}\text { Systolic blood } \\
\text { pressure on } \\
\text { admission }(\mathrm{mmHg})\end{array}$ & Score & $\begin{array}{l}\text { Baseline } \\
\mathrm{Hb}(\mathrm{g} / \mathrm{dl})\end{array}$ & Score & $\begin{array}{c}\text { Heart rate on } \\
\text { admission } \\
\text { (bts/min) }\end{array}$ & Score \\
\hline$\leq 40$ & 0 & $<0.8$ & 0 & $\leq 90$ & 4 & $<5$ & 17 & $\leq 40$ & 0 \\
\hline $41-50$ & 1 & $0.8-1.59$ & 1 & $91-100$ & 3 & $5-7.9$ & 15 & $41-60$ & 2 \\
\hline $51-60$ & 2 & $1.6-1.99$ & 2 & $101-120$ & 2 & $8-9.9$ & 13 & $61-70$ & 3 \\
\hline $61-70$ & 3 & $2.0-2.99$ & 4 & $121-140$ & 1 & $10-10.9$ & 12 & $71-80$ & 5 \\
\hline $71-80$ & 4 & $3.0-3.99$ & 6 & $141-170$ & 0 & $11-13.9$ & 9 & $81-100$ & 6 \\
\hline $81-90$ & 5 & $4.0-4.99$ & 8 & $171-200$ & 1 & $14-15.9$ & 6 & $101-110$ & 8 \\
\hline \multirow[t]{3}{*}{$\geq 91$} & 6 & $5.0-5.99$ & 10 & $\geq 201$ & 2 & $\geq 16$ & 2 & $111-120$ & 9 \\
\hline & & $\geq 6$ & 11 & & & & & $121-130$ & 11 \\
\hline & & Dialysis & 11 & & & & & $\begin{array}{r}131-150 \\
\geq 151\end{array}$ & $\begin{array}{l}12 \\
14\end{array}$ \\
\hline \multicolumn{2}{|c|}{ Weight (kg) } & Score & Gender & Score & \multicolumn{2}{|c|}{ Home warfarin use } & Score & $\begin{array}{l}\text { Diabetes } \\
\text { mellitus }\end{array}$ & Score \\
\hline \multicolumn{2}{|c|}{$\leq 50$} & 5 & Female & 4 & \multicolumn{2}{|r|}{ No } & 0 & No & 0 \\
\hline \multicolumn{2}{|c|}{$51-70$} & 4 & Male & 0 & \multirow{2}{*}{\multicolumn{2}{|c|}{ Yes }} & 2 & Yes & 3 \\
\hline \multirow{2}{*}{\multicolumn{2}{|c|}{$\begin{array}{c}71-100 \\
101-120\end{array}$}} & 3 & & & & & & & \\
\hline & & 2 & & & & & & & \\
\hline \multicolumn{2}{|c|}{$121-140$} & 1 & & & & & & & \\
\hline \multicolumn{2}{|c|}{$\geq 141$} & 0 & & & & & & & \\
\hline \multicolumn{2}{|c|}{$\begin{array}{c}\text { Heart failure } \pm \\
\text { shock on admission }\end{array}$} & \multicolumn{2}{|c|}{ Score } & ECG changes & \multicolumn{2}{|c|}{ Score } & $\begin{array}{r}\text { Previc } \\
\text { periph } \\
\text { arteryd }\end{array}$ & $\begin{array}{l}\text { ously } \\
\text { heral } \\
\text { lisease }\end{array}$ & Score \\
\hline \multicolumn{2}{|c|}{ None } & \multicolumn{2}{|c|}{0} & $\begin{array}{l}\text { No ST-segment } \\
\text { changes }\end{array}$ & \multicolumn{2}{|r|}{0} & $\mathrm{Nc}$ & & 0 \\
\hline Heart failu & only & 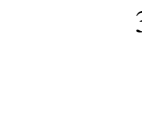 & & $\begin{array}{c}\text { ST-segment } \\
\text { depression or } \\
\text { transient elevation }\end{array}$ & & 3 & $\mathrm{Ye}$ & es & 3 \\
\hline $\begin{array}{r}\text { Heart failu } \\
\text { shoc }\end{array}$ & with & 1 & & $\begin{array}{c}\text { ST-segment } \\
\text { elevation }\end{array}$ & & 7 & & & \\
\hline
\end{tabular}




\begin{tabular}{|c|c|c|c|c|c|c|c|}
\hline \multicolumn{8}{|c|}{ CRUSADE bleeding score } \\
\hline $\begin{array}{c}\text { Baseline } \\
\text { hematocrit }\end{array}$ & Score & $\begin{array}{l}\text { Systolic blood } \\
\text { pressure }\end{array}$ & Score & $\begin{array}{l}\text { Creatinine } \\
\text { clearance }\end{array}$ & Score & $\begin{array}{l}\text { Heart } \\
\text { rate }\end{array}$ & Score \\
\hline$<31$ & 9 & $91-100$ & 8 & $>15-30$ & 35 & $71-80$ & 1 \\
\hline $31-33.9$ & 7 & $101-120$ & 5 & $>30-60$ & 28 & $81-90$ & 3 \\
\hline $34-36.9$ & 3 & $121-180$ & 1 & $>60-90$ & 17 & $91-100$ & 6 \\
\hline \multirow[t]{3}{*}{$37-39.9$} & 2 & $181-200$ & 3 & $>90-120$ & 7 & $101-110$ & 8 \\
\hline & & $\geq 201$ & 5 & $>120$ & 0 & $111-120$ & 10 \\
\hline & & & & & & $\geq 121$ & 11 \\
\hline Diabetes mellitus & Score & $\begin{array}{l}\text { Prior vascular } \\
\text { disease }\end{array}$ & Score & Heart failure & Score & Female & Score \\
\hline No & 0 & No & 0 & No & 0 & No & 0 \\
\hline Yes & 6 & Yes & 6 & Yes & 7 & Yes & 8 \\
\hline
\end{tabular}

\begin{tabular}{lll}
\hline \multicolumn{1}{c}{ Papworth bleeding score } \\
\hline Riskfactor & Scoree $=0$ & Score $=1$ \\
\hline Surgery priority & Elective & Urgent or emergency \\
Surgery Type & CABG or single valve & All other surgery types \\
Aortic valve disease & None & Stenosis, regurgitation, both \\
BMI & BMI greater/equal to 25 & BMI less than 25 \\
Age & Younger than 75 & 75 years or older
\end{tabular}

\begin{tabular}{lc}
\hline & TRACK bleeding score \\
\hline Factor & Score \\
\hline Age $>67$ years & 6 \\
Weight $<60 \mathrm{~kg}(\mathrm{~F}), 85 \mathrm{~kg}(\mathrm{M})$ & 2 \\
Female & 4 \\
Complex surgery & 7 \\
Hematocrit & 1 point per each value $(\%)$ below $40 \%$
\end{tabular}

\begin{tabular}{lc}
\hline & TRUST bleeding score \\
\hline Variable & Score \\
\hline Hemoglobin level $<135 \mathrm{~g} / \mathrm{L}$ & 1 \\
Weight $<77 \mathrm{~kg}$ & 1 \\
Female sex & 1 \\
Age $>65$ years & 1 \\
Non elective surgery & 1 \\
Serum creatinine level $>120 \mu \mathrm{mol} / \mathrm{L}$ & 1 \\
Previous cardiac surgery & 1 \\
Non-isolated surgery & 1 \\
\hline
\end{tabular}


Supplemental Table 2. Reclassification using the WILL-BLEED score compared to other bleeding risk scores in predicting E-CABG bleeding grades 2-3.

\begin{tabular}{|c|c|c|c|c|}
\hline $\begin{array}{l}\text { Bleeding scores and } \\
\text { risk categories }\end{array}$ & Low risk & Intermediate risk & High risk & Total \\
\hline \multicolumn{5}{|c|}{ ACTION bleeding score } \\
\hline $\begin{array}{l}\text { Low risk } \\
(<5 \%)\end{array}$ & $51(73.1)$ & $14(20.3)$ & $4(5.8)$ & 69 \\
\hline $\begin{array}{l}\text { Intermediate risk } \\
(5-11 \%)\end{array}$ & $22(23.9)$ & $38(41.3)$ & $32(34.8)$ & 92 \\
\hline $\begin{array}{l}\text { High Risk } \\
(>11 \%)\end{array}$ & $2(3.1)$ & $12(18.5)$ & $51(78.5)$ & 65 \\
\hline Total & 75 & 64 & 87 & 226 \\
\hline \multicolumn{5}{|c|}{ CRUSADE bleeding score } \\
\hline $\begin{array}{l}\text { Low risk } \\
(<5 \%)\end{array}$ & $45(60.8)$ & $24(32.4)$ & $5(6.8)$ & 74 \\
\hline $\begin{array}{l}\text { Intermediate risk } \\
(5-11 \%)\end{array}$ & $29(30.5)$ & $32(33.7)$ & $34(35.8)$ & 95 \\
\hline $\begin{array}{l}\text { High Risk } \\
(>11 \%)\end{array}$ & $1(1.8)$ & $8(14.0)$ & $48(84.2)$ & 57 \\
\hline Total & 75 & 64 & 87 & 226 \\
\hline \multicolumn{5}{|c|}{ TRACK bleeding score } \\
\hline $\begin{array}{l}\text { Low risk } \\
(<5 \%)\end{array}$ & $25(46.3)$ & $21(38.9)$ & $8(14.8)$ & 54 \\
\hline $\begin{array}{l}\text { Intermediate risk } \\
(5-11 \%)\end{array}$ & $49(41.5)$ & $34(28.8)$ & $35(29.7)$ & 118 \\
\hline $\begin{array}{l}\text { High Risk } \\
(>11 \%)\end{array}$ & $1(1.9)$ & $9(16.7)$ & $44(81.5)$ & 54 \\
\hline Total & 75 & 64 & 87 & 226 \\
\hline \multicolumn{5}{|c|}{ TRUST bleeding score } \\
\hline $\begin{array}{l}\text { Low risk } \\
(<5 \%)\end{array}$ & $31(75.6)$ & $10(24.4)$ & 0 & 41 \\
\hline $\begin{array}{l}\text { Intermediate risk } \\
(5-11 \%)\end{array}$ & $38(40.0)$ & $34(35.8)$ & $23(24.2)$ & 95 \\
\hline $\begin{array}{l}\text { High Risk } \\
(>11 \%)\end{array}$ & $6(6.7)$ & $20(22.2)$ & $64(71.1)$ & 90 \\
\hline Total & 75 & 64 & 87 & 226 \\
\hline \multicolumn{5}{|c|}{ Papworth bleeding score } \\
\hline $\begin{array}{l}\text { Low risk } \\
(<5 \%)\end{array}$ & $50(59.5)$ & $19(22.6)$ & $15(17.9)$ & 84 \\
\hline $\begin{array}{l}\text { Intermediate risk } \\
(5-11 \%)\end{array}$ & $24(17.7)$ & $45(33.1)$ & $67(49.3)$ & 136 \\
\hline $\begin{array}{l}\text { High Risk } \\
(>11 \%)\end{array}$ & $1(16.7)$ & 0 & $5(83.3)$ & 6 \\
\hline Total & 75 & 64 & 87 & 226 \\
\hline
\end{tabular}

Values are counts and percentages (in parentheses). 